DOI: 10.30519/ahtr.656469

Advances in Hospitality and Tourism Research (AHTR)

\title{
THE MEDIATING ROLE OF MEANING IN LIFE IN THE RELATIONSHIP BETWEEN MEMORABLE TOURISM EXPERIENCES AND SUBJECTIVE WELL-BEING
}

\author{
Duygu AYDIN 1 \\ The Institute of Social Sciences, Akdeniz University, Turkey \\ ORCID: 0000-0002-5592-1339 \\ Ece OMURIS \\ Department of Tourism Management, Akdeniz University, Turkey \\ ORCID: 0000-0002-1485-2816
}

\begin{abstract}
Due to varying tourist motivations and needs, involvement in new experiences has different individual consequences. This paper examines the predictive relationship between memorable tourism experience (MTE), meaning in life (MIL) and subjective well-being (SWB). It further investigates whether meaning in life mediates memorable tourism experience's influence on subjective well-being. The study design was cross-sectional, with data collected from 283 tourists visiting Cappadocia, Turkey. Although all variables were positively correlated, SEM analyses revealed that meaning in life mediated the association of memorable tourism experience with life satisfaction but not positive affect. These findings are discussed considering the role of meaning in life in the link between dimensions of MTE and SWB.
\end{abstract}

Article History

Received 11 December 2019

Revised 30 October 2020

Accepted 1 November 2020

\section{Keywords}

Memorable tourism experience Subjective well-being

Meaning in life

\section{INTRODUCTION}

Tourist experience is frequently addressed in interdisciplinary studies, such as marketing, sociology and psychology (Cohen, 1979; Uriely, 2005; Larsen, 2007). By acting as a bridge between tourist's self-identities and the real

\footnotetext{
${ }^{1}$ Address correspondence to Duygu AYDIN, Doctoral Student, Tourism Management Programme, The Institute of Social Sciences, Akdeniz University, Antalya, TURKEY. E-mail: daydin93@gmail.com
} 
world, this experience enables individuals to meet their both affective and cognitive inquiries (Handler \& Saxton, 1988; Pine \& Gilmore, 2011). The desire to experience something different than the typical tourism product or service, such as seeking more meaningful experiences, has led to new trends in tourism behavior. Recent research shows a transition towards extraordinary, extroverted tourist typologies rather than organized mass tourist typologies (Uriely et al., 2002; Cornelisse, 2014). The basis of this change in tourist motivation is a search for unique and memorable tourism experiences, through which individuals can find deeper meaning about themselves and the environment, and feel themselves physically, mentally, and intellectually immersed within them (Uriely et al., 2002; Cornelisse, 2014). With the changing demand for tourism, the factors that make an experience unique and memorable, and the effects of experiences on individuals have become a focus of recent studies (Kim et al. 2012; Chandralal et al., 2015; Sthapit \& Coudounaris, 2018).

Memorable tourist experience (MTE) depends on the individual's expectations, positive affect during or after the event, and the extent that those memories are remembered. Three factors play a significant role: individual discovery, intellectual development, and social relations (Tung \& Ritchie, 2011a). What makes an experience memorable are factors that appeal to an individual's senses of taste, hearing, sight, touch and smell, feelings about the event and the environment, as well as changing thoughts and behaviors during events (Ballantyne et al., 2011). The memorable tourism experience is used as an escape, problem-solver, supplier of strength and new life blood. It has positive effects on happiness (Gilbert \& Abdullah, 2004) and individual well-being and life satisfaction (Sirgy et al., 2000; Boswijk et al., 2007; Tung \& Ritchie, 2011a; Dolnicar et al., 2012; de Freitas Coelho et al., 2018).

Thus, MTE goes far beyond a basic sense of pleasure by providing rich personal exploration wherein individuals enjoy the geography they travel through, participate in the culture of a local community, develop intellectual capacities through new experiences, stay in the moment, and focus on themselves and their life (Chandralal et al., 2015; Loureiro et al., 2019). Considering the changing tourist expectations and typologies, experiencing meaningful activities and events can develop other awareness beyond positive outcomes, such as feeling good and satisfaction. Individuals temporarily suspend the norms and values that govern their lives so as to approach their own lives and the society from a different perspective (Turner \& Ash, 1975). Similarly, individuals participating in tourism activities can question their own existence by feeling themselves to 
be more authentic (Wang, 1999), while cultural heritage sites, like museums, can be seen as centers of interpretation where individuals come to understand themselves and their lives (Uzzell, 1998).

Therefore, it is thought that an experience in which individuals move away from daily life and norms and return to their inner world and question the meaning of life will remain memorable even after a long time. Moreover, it is predicted that a tourism experience in which they have the opportunity to question their lives and life meanings will affect the wellbeing and life satisfaction of individuals in a positive way. However, when the literature on MTE is examined, it is seen that the concept of MTE is not adequately associated with the meaning of life, self-discovery, and existential interpretation. This article aims to contribute to the relevant gap in the literature by exploring what effect it will have on life satisfaction. In this context, visit to the UNESCO-listed and one of Turkey's most important cultural heritage sites, Cappadocia National Park can be considered as memorable tourism experience. Aim of the current study is to contribute to the literature by examining relationship between subjective well-being and this experiences, as well as mediating effect of the meaning of life, Thus, research questions of the study are as follows;

1. Does an MTE significantly influence meaning in life?

2. Does an MTE significantly influence subjective well-being?

3. Does meaning in life mediate the relationship between an MTE and subjective wellbeing?

By using quantitative methods, the study contributes to the literature on subjective well-being by examining its association with MTEs and meaning in life.

In the following section, based on the literature review, a conceptual framework is proposed with research hypotheses that specify the direction of the relationships among the constructs.

\section{MEMORABLE TOURISM EXPERIENCE \& SUBJECTIVE WELL-BEING}

The stress and mental fatigue of daily life that prevents people from satisfying their personal and interpersonal needs is one of the main reasons for interest in tourism and leisure experiences (Iso-Ahola, 1982). Many studies demonstrate that positive tourism experiences increase positive mood, contribute to life satisfaction, support relaxation and personal development, and thereby increase well-being (Andrew \& Withey, 1976; 
Campbell, 1976). Meanwhile, advances in technology provide experiences within everyday life that were once only accessible through tourism. For instance, cultural sites and interesting areas can be easily explored at home through virtual reality screens enabling tourism-related experiences without travelling (Uriely, 2005).

According to Filep (2012, p. 268), "A fulfilling tourist experience is arguably one that is characterized not just by pleasure but also by how personally meaningful tourists found their holiday activities." This raises the question of changing tourist demand. Similarly, it is seen that current studies on tourism and travel focus on memorable tourism experience (Tung \& Ritchie, 2011a), tourist happiness (Nawijn, 2011), meaningful tourism (Noy, 2004), transformative tourism (Lean, 2012), spiritual experiences (Sharpley \& Jepson, 2011), existential experiences (Wang, 1999), recovery experiences of tourism and travel trends (Chen et al., 2016) and the tourist moment (Cary, 2004), rather than just pleasure and entertainment provided by standard tourism activities. It is considered that in understanding current tourist behavior and motivation, memorable tourism experiences that touch the lives of individuals, are of critical importance as they enable them to question their existence and meaning in life, improve their personal development and well-being.

It is stated that if a tourism experience is felt physically, spiritually and intellectually, it will be remembered long after it ends creating a memorable tourism experience (Tung \& Ritchie, 2011a; Kim et al., 2012). Similarly, Ooi (2005), who emphasizes the subjective aspect of memorable experiences, claims that tourists' indications of enjoying the experience do not mean all individuals have memorable experiences at the same level. Different moods, personal emotions, interests, and perspectives mean that touristic products and experiences are interpreted differently. The literature shows that emotional dimensions are frequently associated with memorability (Boswijk et al., 2007; Tung \& Ritchie, 2011b; Slatten et al., 2011; Chandralal et al., 2015; de Freitas Coelho et al., 2018). Individuals collect impressions from the environment through their senses. These impressions later turn into emotional reactions, such as pleasure, fear, or happiness. Emotional reactions in the memories of individuals become important parts of MTEs because these will be remembered. Thus, every remarkable emotion experienced by individuals, whether positive or negative, can provide important mental cues for potentially achieving memorable experience (Boswijk et al., 2007; Slatten et al., 2011; de Freitas Coelho et al., 2018). 
In addition to emotions, the memorability of the experience can be ensured by observation, identification, dialogue, and physical contact enabling tourists to communicate with local people, experience their lives and meet different cultures. Dialogue and physical contact meet various touristic expectations and needs, such as intellectual development and personal change, which foster the memorability of the experience (Tung \& Ritchie, 2011a; Chandralal et al., 2015). Tung and Ritchie (2011a) identified five factors that characterize memorable experiences: identity formation, family milestones, relationship development, nostalgia re-enactment, and freedom pursuits.

Focusing on memory and memorability, Kim et al. (2010) argue that memory of an event is affected by affective feelings, cognitive evaluations and new events. They developed the 24-item Memorable Tourism Experience Scale, with 7 subscales of hedonism, refreshment, local culture, meaningfulness, knowledge, involvement and novelty. They argue that these dimensions are important features of the tourism experience that affect memories. The dimensions are also complementary. For example, emotion is an important aspect of the tourism experience (Kim \& Ritchie, 2014), involved in every stage of the tourism experience. Individuals basically consume tourism and leisure-related products to have feelings such as pleasure and enjoyment (Otto \& Ritchie, 1996; Tung \& Ritchie, 2011a; Kim \& Ritchie, 2014).

Tourism products and services, which are very rich in terms of hedonic purposes, allow individuals to escape from daily life, satisfy their psychological needs and gain a feeling of refreshment (Kim, 2013). They also contribute to intellectual development, expertise, and awareness by giving tourists new geographical, cultural, and historical knowledge (Pearce, 1987). Individuals aim to gain global citizenship, seeking a certain meaning and novelty, especially by choosing destinations that are different to or contrast with their own countries and cultures. These individuals can enrich their experiences by learning the region's local culture, meeting local people, thereby creating valuable and long-lasting memories from their experiences (Manfredo, 1989; Arnould \& Price, 1993; Tung \& Ritchie, 2011a; Cheng \& Lu, 2013; Kim \& Ritchie, 2014; Chandralal et al., 2015).

The literature on memorable tourism experience mostly focuses on behavioral intention (Kim et al., 2010; Chen et al., 2016; Tsai, 2016; Coudounaris \& Sthapit, 2017; Zhang et al., 2018; Huang \& van der Veen, 2019; Sharma \& Nayak, 2019), destination image (Dagustani et al., 2018; Kim, 2018), destination loyalty (Chen \& Rahman, 2018), perceived image 
and intention to recommend (Prayag et al., 2017), and destination branding (Tukamushaba et al., 2016). Leisure studies within positive psychology show that holidays improve subjective well-being (SWB) and quality of life (QoL) (McConkey \& Adams, 2000; Gilbert \& Abdullah, 2004; Neal et al., 2004). SWB and QoL shapes individuals' long-term general experiences by having positive reactions to life (Sirgy et al., 2000; Diener, 2009).

In the memorable tourism experience and extraordinary experience literature, which are considered with the recent tourist typologies and demands, as a result of the tourism experience, well-being is discussed in more detail on a hedonism and eudaimonism basis and an answer is sought for the question of how the well-being of individuals is affected in these contexts (Sirgyet al., 2000; Filep \& Higham, 2014; Knobloch et al., 2017; Sthapit \& Coudounaris, 2018; Vada et al., 2019). Well-being considered as eudaimonia focuses on personal development and functioning, whereas hedonism concerns positive emotions, happiness, and satisfaction (Ryan \& Deci, 2001). Psychological well-being, which falls within the eudaimonia tradition, reflects a deep emotional state that is evaluated over a longer time frame rather than as positive emotions during or immediately after the tourism experience (Vada et al., 2019). Subjective well-being, which has been associated with the hedonistic approach to well-being, is a multifaceted concept of various cognitive and affective structures. Its cognitive aspect is associated with life satisfaction, while affective one reflects positive and negative emotions (Ryan \& Deci, 2001).

Positive and negative emotions enable individuals to evaluate their experiences affectively (Ryan \& Deci, 2001). Ortony and Turner (1990) describe fun, happiness, and love as positive emotions, whereas sadness, irritability, anxiety and stress are negative emotions. It is argued that tourists experience positive emotions from forming positive relationships with local people, participating in pleasant activities at the destination, and experiencing local culture and their knowledge. Because individuals attribute their positive feelings to their experiences, the destination becomes a "home of the heart", thereby making their experiences memorable (Keller, 2003). Therefore, the present study hypothesizes that MTEs increase wellbeing by stimulating positive emotions.

H1: There is a positive relationship between MTEs and positive and negative emotions.

Satisfaction is traditionally considered to result from service performance that meets the expectations of individuals. Life satisfaction, which represents the cognitive aspect of subjective well-being, is defined as 
a cognitive process in which individuals evaluate all living conditions, such as social relationships, occupation, education, and family, as a whole (Diener et al., 1999). According to Westbrook and Oliver (1991), satisfaction varies according to underlying emotional dimensions. High satisfaction occurs with high-level positive emotions, such as pleasure, surprise, and happiness, whereas low satisfaction occurs in non-emotional situations or with negative emotions. Given that positive emotions are included in the hedonism dimension, MTEs increase life satisfaction (Zhong et al., 2017). The experiential aspects of tourism, such as awareness, participation, peace of mind, and hedonism, provide a different satisfaction beyond service quality (Otto \& Ritchie, 1996). An individual who considers an experience as memorable one, in many ways experiences strong positive emotions. This in turn increases life satisfaction and improves subjective well-being. This leads to the second hypothesis:

$\mathrm{H} 2$ : There is a positive relationship between MTEs and life satisfaction.

\section{THE MEDIATING ROLE OF MEANING IN LIFE}

A fulfilling tourism experience is characterized not only by pleasure but also by how tourists personally find holiday activities meaningful. Although subjective well-being sheds light on the tourist experience and focuses on whether the individual feels good or bad, tourists not only focus on pleasure but also evaluate what is good or bad and meaningful about their lives (Filep, 2012). This may be related to Maslow's (1943) concept of self-actualization in terms of encountering a deeper meaning beyond material existence and to finding a sense of value (Cornelisse, 2014; Uriely, 2005). For example, Noy (2004) claims that backpackers seek self-change, while adventure and authenticity often characterize their self-change experiences. For Wilson and Harris (2006), meaningful travel includes themes of self and identity, self-empowerment and commitment to others (global citizenship). That is, individuals focus more on the nature of existence than pleasure, seeking a unique and memorable tourism experience to question or find a certain meaning of their lives.

From a qualitative study on the factors that make people's tourism experiences memorable, Chandralal and Valenzuela (2013) concluded that important personal outcomes, such as self-development, relationship development, and developing family well-being, depend on the perceived significance of the experience. Through new experiences, individuals improve their intellectual capacities, expand their perspective on life, 
change their self-identity and discover new talents. These experiences all increase their sense of meaning in life. Similarly, relations developed with local people in the region of travel play an important role in an individual's acquisition of a universal citizen self-identity (Chandralal \& Valenzuela, 2013).

Emphasizing the catalytic effect of meaningfulness in personal development and change, Kim et al. (2012) argue that the meaningfulness of memorable experiences contributes significantly to individuals' personal lives. Therefore, the meaning of life plays an important role in the positive effects of MTEs on positive affect and life satisfaction. Because previous studies addressing tourist happiness in terms of subjective well-being are incomplete, further research strengthened with other psychometric scales is needed (Filep, 2012). Accordingly, the present study investigates the relationship between MTEs and life satisfaction by determining the mediating role of meaning in life. This leads to the following three hypotheses:

H3: There is a positive relationship between MTEs and meaning in life.

H4: Meaning in life mediates the effect of MTEs on positive affect.

$\mathrm{H} 5$ : Meaning in life mediates the effect of MTEs on life satisfaction.

\section{METHODOLOGY}

\section{Participants and Procedure}

Individuals wishing to encounter deep meanings beyond a standard product and service experience, find themselves, understand life and see cultural heritage areas as original experiences that speak to the cultural elements of their life (Uzzell, 1998; Uriely, 2005; Cornelisse, 2014). In addition to the personal aspects of authenticity, such as the true self and being loyal to the essence, the concrete and abstract aspects of the originality and reality of cultural artefacts and events become prominent (Steiner \& Reisinger, 2006). Similarly, in addition to the criteria that constitute the outstanding universal values of the UNESCO World Heritage List, there are various concrete and abstract originality criteria, such as form and design, materials and substance, location and environment, tradition and techniques, spirit and feeling.

To test mediating role of meaning in life between MTEs and wellbeing relationships, a survey instrument was designed to gather data in Göreme, a UNESCO World Heritage Site, located in Cappadocia, Turkey. 
The area is a popular tourist destination with cultural attractions. Cappadocia provides a significant combination of abstract and tangible authenticity - the latter formed as a result of wind and water erosion, such as fairy chimneys and tall natural columns topped by balanced rocks. The area also has steep valleys bearing the traces of ancient civilizations, underground cities, churches, and houses carved into rocks, fine wineries and local pottery (Yolal \& Karacaoglu, 2017). Hot air ballooning, trekking, cycling, and horseback riding are also prime tourism experiences in the area (Erdogan \& Tosun, 2009). By offering such varied experiences in a unique atmosphere, Cappadocia creates an opportunity for tourists to seek deeper meaning by removing them from their routine lives. It also creates MTEs that can improve tourists' well-being through examining their self and life meaning.

Using convenience sampling, surveys in both English and Turkish were handed out to tourists who had either completed or were about to complete their visit to Cappadocia. Data were collected voluntarily through one-on-one communication with the participants. Although 657 responses were collected, 374 forms were eliminated due to missing values, outliers, or non-normality and non-linearity. Of the 283 participants providing usable data, $59.1 \%(\mathrm{~N}=166)$ were female and $40.9 \%$ were male $(\mathrm{N}=115)$. Regarding age, $10.1 \%(\mathrm{~N}=28)$ were 20 years old or younger, $40.6 \%(\mathrm{~N}=113)$ were between 21 and 30, 22.3\% ( $=62)$ were between 31 and 40, 11.2\% $(\mathrm{N}=31)$ between 41 and 50 and $15.8 \%(\mathrm{~N}=44)$ were at least 51 years old. The majority had a monthly income of $350 \$$ or less. Finally, $4 \%(\mathrm{~N}=11)$ were primary school graduates, $23.8 \%$ were high school graduates $(\mathrm{N}=65), 34.8 \%$ were university graduates $(\mathrm{N}=95)$ and $37.4 \%(\mathrm{~N}=102)$ had a post-graduate education.

Table 1. Demographic Characteristics

\begin{tabular}{lccclccc}
\hline & $\mathbf{N}$ & $\mathbf{\%}$ & Total & $\mathbf{N}$ & $\mathbf{\%}$ & Total \\
\hline Age & & & 278 & Education & & & 273 \\
20 and younger & 28 & 10.1 & & Primary school & 11 & 4 & \\
$21-30$ & 113 & 40.6 & & High school & 65 & 23.8 & \\
$31-40$ & 62 & 22.3 & & Undergraduate & 95 & 34.8 & \\
$41-50$ & 31 & 11.2 & & Graduate & 102 & 37.4 & \\
51 and older & 44 & 15.8 & & Income & & & 244 \\
Gender & & & 281 & 350 or less & 81 & 33.2 & \\
Female & 166 & 59.1 & & 350 \$-500 & 47 & 19.3 & \\
Male & 115 & 40.9 & & 501\$-600 & 41 & 16.8 & \\
& & & & $601 \$$ or more & 75 & 30.7 & \\
\hline
\end{tabular}


As Table 1 shows, the majority of participants were female, high education graduates, with a monthly income level of $350 \$$ or less, aged between 21 and 30 .

\section{Instruments}

The questionnaire had three sections. The first section provided information on the research aims, data confidentiality and participant anonymity. It also stated that the questions had no correct or incorrect answers, while participants were asked to answer questions as honestly as possible. Because bias can occur if respondents' answers are influenced by lenience and social desirability, respondents were reassured about anonymity and possible concerns about being evaluated to reduce common method variance (Podsakoff et al., 2003).

The second section included four scales to assess the research variables: Memorable Tourism Experience Scale (MTES), Positive and Negative Affect Schedule (PANAS), Meaning in Life Scale (MLQ), and Satisfaction with Life Scale (SWLS). Except for MTES, the scales had been validated in the Turkish literature. The Turkish validation of the MTES questionnaire was administered by two bilingual professionals following back-translation. One translated the scales from English to Turkish, while the other did the same from Turkish to English. A pilot test for the Turkish MTES was then conducted after semantic equivalence had been established between the translations. The final section of the questionnaire asked about participants' demographic characteristics, such as age, gender, education and income.

Memorable Tourism Experience Scale (MTES). This was developed by Kim et al. (2010) to evaluate a recalled tourism experience. The 24 items are measured on a 7-point Likert-type scale. Kim et al. (2010) argue that a memorable tourism experience has seven dimensions: hedonism (e.g. "I was thrilled about having a new experience in Cappadocia"), refreshment (e.g. "I felt free from daily routine during the trip"), involvement (e.g. "I was interested in the main activities offered"), local culture (e.g. "I had a chance to closely experience the local culture"), meaningfulness (e.g. "I felt that I did something meaningful"), knowledge (e.g. "I gained a lot of information during the trip"), and novelty (e.g. "I had a once-in a lifetime experience"). The Cronbach alpha coefficient was .91 (Kim et al., 2010).

The Turkish version of the MTES was validated by piloting it with 163 participants. SPSS was used to perform an exploratory factor analysis 
(EFA) using principal component analysis to determine the questionnaire's factor structure, followed by confirmatory factor analysis using varimax rotation. Items with factor loadings less than .40 (Hinkin, 1998) and factors with factor loadings higher than .40 but loading onto more than one factor were excluded from the final questionnaire. Specifically, all items for knowledge ("I gained a lot of information during the trip", "I gained a new skill(s) from the trip", "I experienced new culture(s)"), and one item from refreshment ("I had a refreshing experience") were removed from further analyses. After re-running the EFA, a five-factor solution emerged. However, based on Kim et al. (2010) and the Scree plot to clarify the factor structure, the researchers were able to retain the 6-factor scale structure. The reliability coefficient of the new 20-item scale was .92 with a 6-factor structure (refreshment, local culture, involvement, meaningfulness, novelty, hedonism). This structure explained $84 \%$ of the total variance in the scale.

LISREL was then used to perform confirmatory factor analysis (CFA) to test the factor structure and finalize the measurement scale. The results supported the 6-factor model. The model fit index values are shown in Table 2 and it was observed that variables were significant $\left(\chi^{2}=473.79\right.$, $\mathrm{sd}=150, \chi^{2} / \mathrm{sd}=3.15, \mathrm{p}=0.000, \mathrm{RMSEA}=0.087, \mathrm{CFI}=0.91, \mathrm{NFI}=0.87, \mathrm{RFI}=0.84$ ). The factor loadings ranged from .55 to .92 while $t$-values ranged from 9.44 to 18.91 ( $\mathrm{p}<0.001$ ). Thus, the CFA justified use of the 20 -item, 6-dimensional scale, with all items fitting the measurement model.

Table 2. Summary of Goodness-of-fit Statistics for MTES

\begin{tabular}{ccccccccc}
\hline Model & $\chi^{2}$ & $\chi^{2} / \mathbf{s d}$ & RMSEA & GFI & AGFI & CFI & RFI & NFI \\
\hline 6 factors & 473.79 & 3.15 & 0.087 & 0.86 & 0.81 & 0.91 & 0.84 & 0.87 \\
\hline
\end{tabular}

Positive Negative Affect Schedule (PANAS). This scale, developed by Watson et al. (1988), measures positive and negative affect with 10 items each, using a 7-point Likert-type scale. Positive affect (PA) items are attentive, active, alert, enthusiastic, determined, excited, proud, interested, inspired and strong, while negative affect (NA) items are afraid, ashamed, distressed, guilty, nervous, scared, jittery, irritable, upset and hostile. Watson et al. (1988) reported Cronbach alpha coefficients of .88 and .85 for PA and NA, respectively. The scale was translated into Turkish by Gençöz (2000), who reported similar internal consistency coefficients of .86 and .83 for PA and NA, respectively. The internal consistency of items in this study were .80 and .89 for PA and NA, respectively. As suggested by Kim and 
Hatfield (2004), the negative emotion scores of the PANAS score for each participant are reversed and then positive emotions are added to these scores. Thus, positive and negative emotion scores were combined into one dimension to reflect the overall emotional impact of the experience.

Meaning in Life Questionnaire (MLQ). Developed by Steger et al. (2006), this scale measures two dimensions with 5 items each using a 5-point Likert-type scale: Presence of Meaning (MLQ-P) and Search for Meaning (MLQ-S). MLQ-P evaluates the participant's subjective view of meaning in life with items such as "My life has a clear sense of purpose" or "I understand my life's meaning". MLQ-S evaluates the participant's efforts to find meaning in life with items such as "I am always searching for something that makes my life feel significant" or "I am always looking to find my life's purpose". Steger et al. (2006) reported Cronbach alpha coefficients of .86 and .87 for MLQ-P and MLQ-S, respectively. Dursun (2012), who translated the scale into Turkish, reported internal consistency coefficients of .83 and .87 , respectively. In the present study, responses to one item ("My life has no clear purpose") were reverse coded to preserve its meaning. The internal consistency coefficients were 89 for MLQ- S and .79 for MLQ-P.

Satisfaction with Life Scale (SWLS). This scale measures differences in individuals' cognitive assessments of life (Diener, 1984). Diener (1984) argued that it is possible to assess whether individuals are satisfied with their life based on their own subjective criteria as assessed by the questionnaire. The scale has 5 items assessed on a 7-point Likert-type scale, such as "So far I have gotten the important things I want in life" or "In most ways my life is close to my ideal". Diener (1984) reported a Cronbach alpha coefficient of .87. The scale was translated into Turkish by Köker (1991), who reported a Cronbach alpha coefficient of .89. In the present study, the internal consistency coefficient was .84.

\section{Data analysis}

Consistent with the goals of the current study, mediation analysis within a structural equation modeling (SEM) framework was employed to uncover the associations between MTE, meaning in life and subjective wellbeing. The model was tested by path analysis in LISREL 9.30 (Jöreskog \& Sörbom 1993). SEM was used because it provides researchers with tools to test the fit of the model to the data and directly test the significance of mediation effects (Shrout \& Bolger 2002; Kline 2005). 


\section{RESULTS}

\section{Descriptive Statistics and Correlations}

Before testing the research hypotheses, the mean and standard deviations of the variables were examined and the correlation coefficients between the variables were calculated (Table 3$)$. The sub-scales of refreshment $(\mathrm{r}=.278$, $\mathrm{p}<.01)$, local culture $(\mathrm{r}=.276, \mathrm{p}<.01)$, involvement $(\mathrm{r}=.194, \mathrm{p}<.01)$, meaningfulness $(\mathrm{r}=.379, \mathrm{p}<.01)$, novelty $(\mathrm{r}=.324, \mathrm{p}<.01)$, and hedonism $(\mathrm{r}=.197, \mathrm{p}<.01)$ had weak positive correlations with meaning in life.

Regarding the relationship between positive affect and MTE subscales, there were weak positive correlations between refreshment $(\mathrm{r}=.375$, $\mathrm{p}<.01)$, local culture $(\mathrm{r}=.168, \mathrm{p}<.01)$, meaningfulness $(\mathrm{r}=.229, \mathrm{p}<.01)$, novelty $(\mathrm{r}=.268, \mathrm{p}<.01)$, and hedonism $(\mathrm{r}=.265, \mathrm{p}<.01)$ while a moderate positive correlation was found with the involvement $(\mathrm{r}=.414, \mathrm{p}<.01)$. Regarding the relationship between life satisfaction and MTE subscales, there were weak positive correlations with refreshment $(\mathrm{r}=.183, \mathrm{p}<.01)$, local culture $(\mathrm{r}=.134$, $\mathrm{p}<.05)$, involvement $(\mathrm{r}=.260, \mathrm{p}<.01)$, and meaningfulness $(\mathrm{r}=.216, \mathrm{p}<.01)$, novelty $(\mathrm{r}=.225, \mathrm{p}<.05)$ and hedonism $(\mathrm{r}=.172, \mathrm{p}<.05)$. There were weak positive correlations between meaning in life and the refreshment $(\mathrm{r}=.278$, $\mathrm{p}<.01)$, local culture $(\mathrm{r}=.276, \mathrm{p}<.05)$, involvement $(\mathrm{r}=.194, \mathrm{p}<.01)$, meaningfulness $(\mathrm{r}=.379, \mathrm{p}<.01)$, novelty $(\mathrm{r}=.324, \mathrm{p}<.05)$ and hedonism $(\mathrm{r}=.197, \mathrm{p}<.05)$. Regarding the dependent variables, meaning in life positively correlated with positive affect $(\mathrm{r}=.214, \mathrm{p}<.01)$ and life satisfaction $(\mathrm{r}=.261, \mathrm{p}<.01)$. This result supported $\mathrm{H} 1, \mathrm{H} 2$ and $\mathrm{H} 3$.

Table 3. Means, Standard Deviations, and the Correlation Matrix of Study Variables

\begin{tabular}{lccccccccccc}
\hline Variables & Mean & SD & $\mathbf{1}$ & $\mathbf{2}$ & $\mathbf{3}$ & $\mathbf{4}$ & $\mathbf{5}$ & $\mathbf{6}$ & $\mathbf{7}$ & $\mathbf{8}$ & $\mathbf{9}$ \\
\hline 1. Refreshment & 6.05 & .839 & - & & & & & & & \\
2. Local Culture & 5.61 & 1.178 & $.492^{* *}$ & - & & & & & & \\
3. Involvement & 6.15 & .753 & $.532^{* *}$ & $.320^{* *}$ & - & & & & & \\
4. Meaningfulness & 5.67 & .963 & $.639^{* *}$ & $.404^{* *}$ & $.509^{* *}$ & - & & & & \\
5. Novelty & 5.91 & .938 & $.641^{* *}$ & $.549^{* *}$ & $.535^{* *}$ & $.535^{* *}$ & - & & & \\
6. Hedonism & 6.15 & .730 & $.514^{* *}$ & $.451^{* *}$ & $.575^{* *}$ & $.452^{* *}$ & $.614^{* *}$ & - & & \\
7. MLQ & 4.91 & .928 & $.278^{* *}$ & $.276^{* *}$ & $.194^{* *}$ & $.379^{* *}$ & $.324^{* *} .197^{* *}$ & - & \\
8. PANAS & 8.41 & .902 & $.375^{* *}$ & $.168^{* *}$ & $.414^{* *}$ & $.329^{* *}$ & $.268^{* *} .265^{* *}$ & $.214^{* *}$ & - \\
9. SWLS & 5.18 & 1.007 & $.183^{* *}$ & $.134^{*}$ & $.260^{* *}$ & $.216^{* *}$ & $.225^{* *} .172^{* *}$ & $.261^{* *}$ & $.157^{* *}$ & - \\
\hline
\end{tabular}

$\mathrm{SD}=$ Standard Deviation, ${ }^{*} \mathrm{p}<.05,{ }^{* *} \mathrm{p}<.01$ 


\section{Testing the mediation model}

The second stage of the study was carried out after determining significant relationships between all the study variables. To examine the relationships between MTES, PANAS, and MLQ, a mediation test with structural equation modelling was applied. Path analysis was performed using LISREL 9.30 to test the relevance of the research model to the data and examine the influence of the mediating variable effects (Kline, 2005).

First, the mediating role of meaning in life in the effect of MTE on subjective well-being was examined. The path analysis showed that there was no significant relationship between meaning in life and positive affect $(t=1.51, p>.05)$.

The model was retested after removing the relationship between meaning in life and positive affect. This model produced a non-significant chi-square test result $(\chi 2(2)=3.04, \mathrm{p}=.37)$ and perfect fit index results (GFI = .99 , AGFI $=.97, \mathrm{RMSEA}=.04, \mathrm{SRMR}=.03, \mathrm{CFI}=1.00)$. The beta coefficients and $t$ values showing the significance of the relationships between the variables in brackets are presented (Figure 1.). MTE positively predicted meaning in life $(\beta=.36, \mathrm{t}=6.51, \mathrm{p}<.05)$ and PANAS, which measures overall affect to explain subjective well-being $(\beta=.38, t=6.92, p<.05)$. Life satisfaction (SWL), which measures the cognitive aspect of subjective wellbeing, was predicted positively by both meaning in life $(\beta=.20, t=3.23$, $\mathrm{p}<.05)$ and MTE $(\beta=.18, \mathrm{t}=2.99, \mathrm{p}<.05)$.

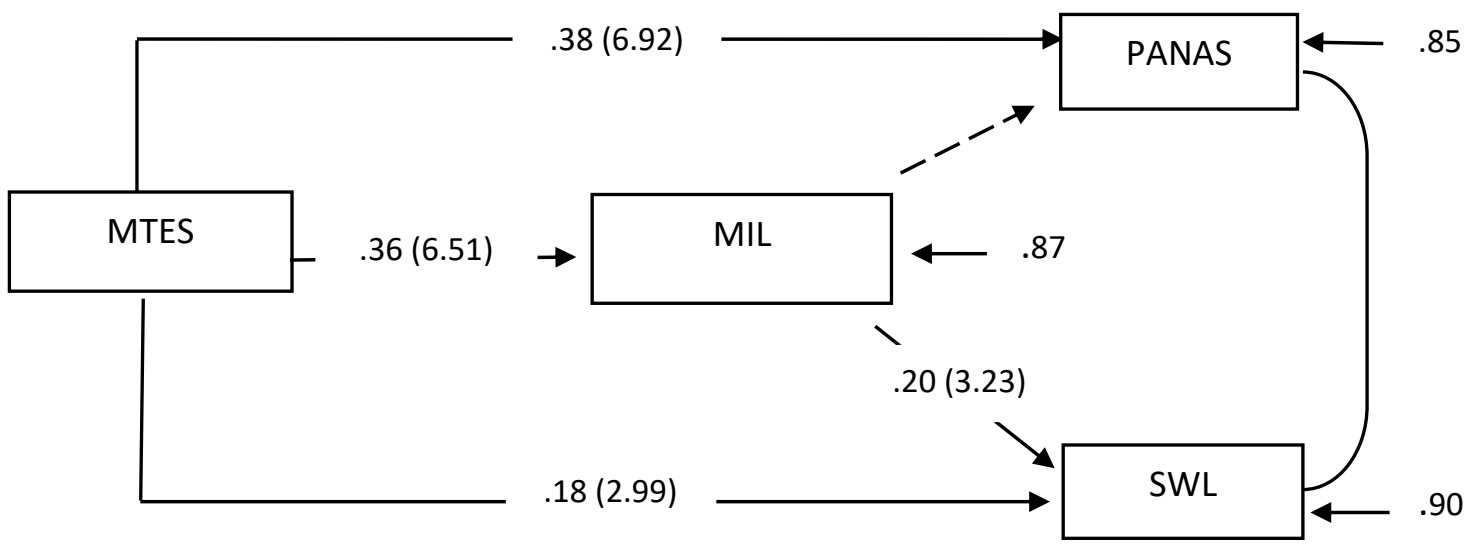

Figure 1. Path Model of Meditation Role of Meaning in Life Between MTE and Subjective Well-Being (Note: the insignificant relationship is indicated by the dashed line.)

In this study, the recalled MTE directly explained 13\% of the variance in meaning in life and $15 \%$ of positive affect. Taken together, MTE and meaning in life explain $10 \%$ of the variance in life satisfaction. These 
findings indicate that meaning in life partially mediates the effect of a memorable tourism experience on life satisfaction (indirect effect $=.10$, $\mathrm{t}=2.89, \mathrm{p}<.05)$.

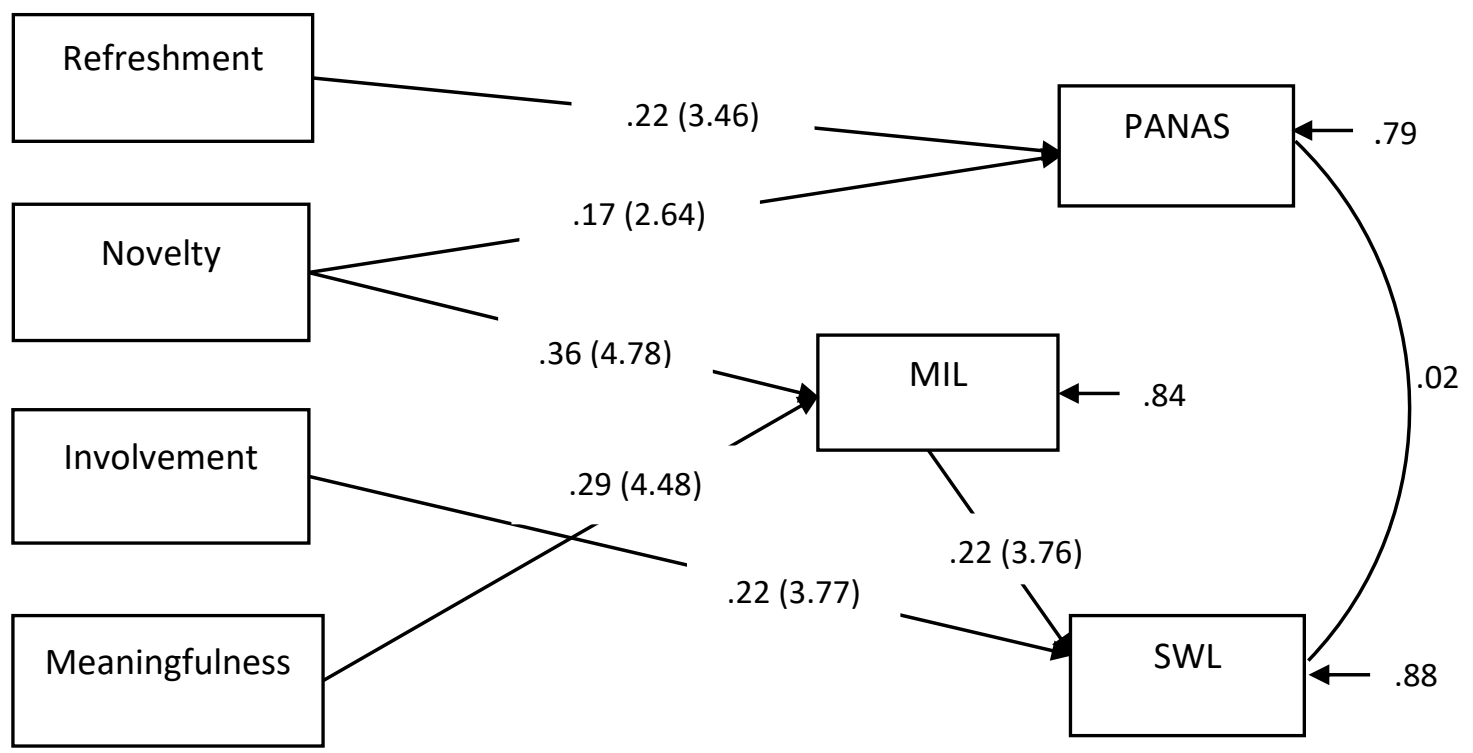

Figure 2. Path Model for the Mediating Role of Meaning in Life between MLES dimensions and Subjective Well-Being

In the second phase, another path analysis was conducted to determine the mediating role of meaning in life in the effect of the MTE subscales on life satisfaction. The first model test showed no significant relationships between the local culture and meaning in life $(\beta=.11, t=1.65$ $<1.96)$, positive affect $(\beta=-.06, t=-0.89<1.96)$, or life satisfaction $(\beta=-.02, \mathrm{t}$ $=-0.22<1.96)$, as well as between hedonism and meaning in life $(\beta=-.06, t=$ $-0.83<1.96)$, positive affect $(\beta=-.01, t=-0.38<1.96)$, and life satisfaction $(\beta=$ $-.02, \mathrm{t}=-0.26<1.96)$. The model was then re-tested by removing the following as there was an insignificant relationship between refreshment and meaning in life $(\beta=-.04, \mathrm{t}=0.46<1.96)$ and life satisfaction $(\beta=-.03, \mathrm{t}=$ $-0.36<1.96)$ : novelty and positive affect $(\beta=-.03, t=-0.32<1.96)$ and life satisfaction $(\beta=.08, \mathrm{t}=0.91<1.96)$; involvement and meaning in life $(\beta=-.04$, $\mathrm{t}=-0.56<1.96)$; meaningfulness and positive affect $(\beta=.05, \mathrm{t}=1.06<1.96)$ and life satisfaction $(\beta=.03, t=0.45<1.96)$; meaning of life and positive affect $(\beta=.11, t=1.55<1.96)$. The chi-square test result for the model with only significant relationships was insignificant $\left(\chi^{2}(8)=6.46, p=.59\right)$ with perfect fit index results $(\mathrm{GFI}=.99$, $\mathrm{AGFI}=.98$, $\mathrm{RMSEA}=.00, \mathrm{SRMR}=.02$, $\mathrm{CFI}=1.00)$. There was a significant relationship between refreshment and positive affect $(\mathrm{t}=3.46, \mathrm{p}<.05)$, novelty and meaning in life $(\mathrm{t}=2.64, \mathrm{p}<.05)$, positive affect and involvement $(t=4.78, \mathrm{p}<.05)$ and life satisfaction $(t=3.77$, 
$\mathrm{p}<.05)$, and between meaningfulness and meaning in life $(\mathrm{t}=4.48, \mathrm{p}<.05)$. The beta coefficients of the model and $t$ values in brackets are shown in Figure 2.

In the model in Figure 2, the effect of the novelty subscale on life satisfaction and the effect of meaning in life on life satisfaction $(\beta=.06, t=$ $2.88, \mathrm{p}<.05$ ) had a full mediating role (indirect effect coefficient. $=.04, \mathrm{t}=$ $2.16, \mathrm{p}<.05)$. This model explained $21 \%$ of positive/negative emotions, which is related to the affective aspect of subjective well-being, $12 \%$ of life satisfaction explaining the cognitive aspect of subjective well-being, and $16 \%$ of meaning in life. Therefore, $\mathrm{H} 4$ and $\mathrm{H} 5$ are partial accepted.

\section{DISCUSSION}

Research into the tourism experience shows how memorable ones affect subjective and psychological well-being (Knobloch et al., 2017; Sthapit, 2018). It also reveals what comprises these memorable experiences (Kim et al., 2012; Chandralal et al., 2015; de Freitas Coelho et al. 2018) and how individual well-being is affected (Sthapit, 2018). Authenticity, meaningfulness, spirituality and transformation, which indicate changing tourist demand, are also associated with the affect and well-being of tourists (Uriely, 2005; Cornelisse, 2014). Therefore, meaningfulness and the self are prominent in extraordinary and memorable tourism experiences. The current study went further than previous research to determine whether meaning in life mediates between the MTE of tourists visiting Cappadocia at Turkey and their SWB. It also investigated the mediating role of meaning in life on the relationships between SWB and MTE dimensions to understand in detail the structure of MTEs of visitors to Cappadocia.

This study first examined the effects of MTES on life meaning and subjective well-being dimensions. This showed that MTES positively affects life satisfaction (representing the cognitive aspect of subjective well-being), positive and negative emotions (representing the affective aspect), and meaning in life. Considering the mediating role of meaning in life, which was the main focus of the study, the findings showed that meaning in life mediated the effect of MTES on life satisfaction but had no mediating role in its effect on positive and negative affect. When considering affective and cognitive processes people had during their experience positive and negative affect, such as pleasure, happiness, anxiety, and stress felt during the experience, are immediate reactions. In contrast, life satisfaction, which treats life as a whole, involves a deeper process (Diener, 2009). 
An individual who considers an experience as memorable will have feelings like happiness, fun, and pleasure without questioning meaning in life and the multifaceted positive/negative situations. The literature on positive and negative affect and MTES show that individuals who have a memorable experience frequently express positive affect, such as happiness, pleasure and excitement (Chandralal \& Valenzuela, 2013). Furthermore, there are significant relationships between positive emotions, memory and MTES (Brewer 1988; Kim, 2010). This study also showed that an individual, who is in search of self, identity and meaning in life, not only considers the experience as memorable, but develops a sense of satisfaction by stimulating meaning in life. The literature also demonstrates that individuals searching for what is good or bad about their lives, need selfactualization to encounter deeper meaning, by going beyond material existence and developing a certain sense of value and satisfaction about life (Maslow, 1943; Uriely, 2005; Filep, 2012; Cornelisse, 2014).

For example, individuals visiting Cappadociacan realize themselves in different ways through the region's unique geography, trekking routes, cultural heritage areas and varied recreational activities. They feel a certain sense of satisfaction with their lives by gaining something from the activities they participate in, while their life meaning is improved.

The second aim of this study was to explore whether meaning in life mediates the effect of MTES subscales on subjective well-being. The results show that the novelty and meaningfulness subscales within life satisfaction fully mediate meaning in life. Considering the area where the research was carried out, recreational activities could include hot air balloon tours, pottery making, or visiting unique cultural heritage sites, such as Cappadocia National Park, Göreme, Zelve, and Pasha vineyards, which are included in the UNESCO Heritage List. Tourists could also participate in gastronomic experiences, such as wine tasting, to meet their needs and quest for novelty.

Similarly, new cultures enable individuals to question their selfidentity and meaning in life through authentic activities. Tourists think they have an MTE by having the opportunity to look at life from a different perspective, which improves their life satisfaction. The literature shows that novelty is the factor defining the multidimensional aspect of human motivation (Lee \& Crompton, 1992). Individuals will reward themselves psychologically as a result of traveling to a new, unfamiliar environment (Berlyne, 1950). Discovering a new destination and culture will help them perceive their experiences in a meaningful way (Iso-Ahola, 1982). 
Moreover, individuals searching for meaning in their lives (Frank, 1985) seek unique experiences that provide a sense of completion rather than just authenticity or escape (Noy, 2004; Novelli \& Robinson, 2005). The emphasis on the fact that finding a certain meaning in life will create a sense of life satisfaction in individuals (Noy, 2004; Novelli \& Robinson, 2005) echoes the findings in the literature.

Moreover, the stress and negative conditions that individuals encounter in their daily lives can damage their life balance. Therefore, a pleasant trip is essential for finding a balance in one's life and escaping from the daily routine (Crompton, 1979). Therefore, individuals who had a memorable experience in Cappadocia escaped from their routine lives and felt good because of their positive emotions and refreshment. By participating in various regionally specific activities, individuals increased positive affective feelings, such as happiness, surprise and entertainment. These positive feelings in turn increased life satisfaction. Similarly, the literature frequently emphasizes that participating in various activities in tourism experiences strongly determines emotions (Pine \& Gilmore, 2011; Slattenet al., 2011; Kim \& Ritchie, 2014; Sthapit \& Coudounaris, 2018). Changing tourist typologies and tourist demands have pushed purchasing motivations and tourism experience outcomes far beyond the pleasure factor. They aim to create valuable experiences in which individuals move away from their daily environment in search of their true self and life purpose. By travelling to new destinations and participating in different activities, individuals gain different perspectives as they engage with the local culture and local people they meet. In addition to a sense of pleasure in their experiences, their participation in various activities allow them to discover new atmospheres, different local cultures and feel revitalized. Likewise, research on memorable experiences shows that these are an important factor in understanding changing motivations and managing demand.

Regarding the study's theoretical contribution, firstly, it explored meaning in life as an important mediator of the effect of MTE on subjective well-being. Secondly, individuals who are in search of meaning and identity do not gain life satisfaction directly through memorable experiences and they experience a certain sense of satisfaction as stimulation of the subscales of meaning in life and the meaningfulness interact with one another. Finally, the mediating role of participation between affective and cognitive processes in an MTE allows individuals to experience a holistic sense of well-being. 
The research has several limitations. First, there was a language barrier to data collection because Cappadocia mainly hosts tourists from Asian and Latin countries but the questionnaires were only prepared in English and Turkish. Surveys in other languages to address the tourist profiles who frequently visit the region could provide more comprehensive data. Another limitation specific to the region is time since the average stay is just 2-3 days. The data was collected from participants who had either just completed their vacation or were about to complete it. Thus, they may have been feeling intense emotions about their vacation. Therefore, future studies could consider a more effective time period for data collection to obtain a more objective perspective on recalled touristic experiences.

Regarding the limitations of content of the study, MTES developed by Kim et al. (2010) was used for data collection. However, when the items of scale were examined, it is understood that only the positive side of memorable experiences is taken into consideration. The feedback obtained from the participants during the data collection phase revealed that the positive emotions encountered are not the only factor that makes an experience memorable, but also the negative ones are very important. Therefore, it is recommended that future studies focus on addressing both positive and negative memorable experiences. At this point, the MTE scale revised by Kim et al. (2012), which includes positive and negative feelings, can be suggested to researchers. It is also thought that new measurement tools to be developed regarding the memorable tourism experience will enable a better understanding of the concept. In addition, researching other dimensions that mediate the effects of MTEs on subjective well-being could significantly contribute to increasing the depth of understanding of MTEs. Similarly, individuals are searching for self-identity, as well as meaning in life. This raises the question of what effects memorable experiences have on the search for relevant identity. Examining this problem in terms of identity theory and social identity theory is highly recommended for future studies.

\section{REFERENCES}

Andrew, F. M., \& Withey, S. B. (1976). Social indicators of well-being. New York and London: Plenum, 20(31), 696-717.

Arnould, E. J., \& Price, L. L. (1993). River magic: Extraordinary experience and the extended service encounter. Journal of Consumer Research, 20(1), 24-45.

Ballantyne, R., Packer, J., \& Sutherland, L. A. (2011). Visitors' memories of wildlife tourism: Implications for the design of powerful interpretive experiences. Tourism Management, 32(4), 770-7.

Berlyne, D. E. (1950). Novelty and curiosity as determinants of exploratory behaviour. British Journal of Psychology, 41(1), 68. 
Boswijk, A., Thijssen, T., Peelen, E., \& Johnston, T. S. B. (2007). The experience economy: A new perspective. Amsterdam: Pearson Education

Brewer, W. F. (1988). Memory for randomly sampled autobiographical events. In U. Neisser \& E. Winograd (Eds.), Remembering reconsidered: Ecological and traditional approaches to the study of memory (pp. 21-90). Cambridge, England: Cambridge University Press.

Campbell, A. (1976). Subjective measures of well-being. American Psychologist, 31(2), 117.

Cary, S. H. (2004). The tourist moment. Annals of Tourism Research, 31(1), 61-77.

Chandralal, L., Rindfleish, J., \& Valenzuela, F. (2015). An application of travel blog narratives to explore memorable tourism experiences. Asia Pacific Journal of Tourism Research, 20(6), 680-693.

Chandralal, L., \& Valenzuela, F. R. (2013). Exploring memorable tourism experiences: Antecedents and behavioural outcomes. Journal of Economics, Business and Management, 1(2), 177-181.

Chen, C. C., Petrick, J. F., \& Shahvali, M. (2016). Tourism experiences as a stress reliever: Examining the effects of tourism recovery experiences on life satisfaction. Journal of Travel Research, 55(2), 150-160.

Chen, H., \& Rahman, I. (2018). Cultural tourism: An analysis of engagement, cultural contact, memorable tourism experience and destination loyalty. Tourism Management Perspectives, 26, 153-163.

Cheng, T., \& Lu, C. (2013). Destination image, novelty, hedonics, perceived value, and revisiting behavioral intention for island tourism. Asia Pacific Journal of Tourism Research, 18(7),766-783.

Cohen, E. (1979). A phenomenology of tourist experiences. Sociology, 13, 179-201.

Cornelisse, M. (2014). Memorable tourist experiences in authentic Vicos, Peru. Journal of Tourism Consumption and Practice, 6(1), 104-127.

Coudounaris, D. N., \& Sthapit, E. (2017). Antecedents of memorable tourism experience related to behavioral intentions. Psychology \& Marketing, 34(12), 1084-1093.

Crompton, J. L. (1979). Motivations for pleasure vacation. Annals of Tourism Research, 6(4), 408-424.

Dagustani, D., Kartini, D., Oesman, Y. M., \& Kaltum, U. (2018). Destination image of tourist: Effect of travel motivation and memorable tourism experience. Etikonomi, 17(2), 307-318.

de Freitas Coelho, M., de Sevilha Gosling, M., \& de Almeida, A. S. A. (2018). Tourism experiences: Core processes of memorable trips. Journal of Hospitality and Tourism Management, 37, 11-22.

Diener, E. (1984). Subjective well-being. Psychological Bulletin, 95(3), 542.

Diener, E. (2009). The science of well-being: The collected works of Ed Diener. New York: Springer.

Diener, E., Suh, E. M., Lucas, R. E., \& Smith, H. L. (1999). Subjective well-being: Three decades of progress. Psychological Bulletin, 125(2), 276.

Dolnicar, S., Yanamandram, V., \& Cliff, K. (2012). The contribution of vacations to quality of life. Annals of Tourism Research, 39(1), 59-83.

Dursun, P. (2012). The role of meaning in life, optimism, hope, and coping styles in subjective wellbeing. Unpublished doctoral dissertation, Middle East Technical University, Ankara.

Erdogan, N., \& Tosun, C. (2009). Environmental performance of tourism accommodations in the protected areas: Case of Göreme Historical National Park. International Journal of Hospitality Management, 28(3), 406-414. 
Filep, S. (2012). Positive psychology and tourism. In M. Uysal, R. Perdue, \& M. Sirgy (eds), Handbook of tourism and quality-of-life research (pp. 31-50). Springer, Dordrecht.

Filep, S., \& Higham, J. (2014). Chasing well-being: New directions for appraising tourist experiences. In T. DeLacy, M. Jiang, G. Lipman, \& S. Vorster (eds), Green growth and travelism: Concept, Policy and Practice for Sustainable Tourism (pp. 112-125). London: Routledge.

Frank, R. H. (1985). Choosing the right pond: Human behavior and the quest for status. Oxford University Press.

Gençöz, T. (2000). Pozitif ve negatif duygu ölçeği: Geçerlik ve güvenirlik çalışması. Türk Psikoloji Dergisi, 15(46), 19-26.

Gilbert, D., \& Abdullah, J. (2004). Holiday taking and the sense of well-being. Annals of Tourism Research, 103-121.

Handler, R., \& Saxton, W. (1988). Dyssimulation: reflexivity, narrative, and the quest for authenticity in "living history". Cultural Anthropology, 3(3), 242-260.

Hinkin, T.R. (1998). A brief tutorial on development of measures for use in survey questionnaires. Organizational Research Methods, 1(1), 104-121.

Huang, S., \& van der Veen, R. (2019). The moderation of gender and generation in the effects of perceived destination image on tourist attitude and visit intention: A study of potential Chinese visitors to Australia. Journal of Vacation Marketing, 25(3), 375-389.

Iso-Ahola, S. E. (1982). Toward a social psychological theory of tourism motivation: A rejoinder. Annals of Tourism Research, 256-262.

Jöreskog, K. G., \& Sörbom, D. (1993). LISREL: Structural equation modeling with SIMPLIS command language. Hillsdale, NJ: Erlbaum and Scientific Software International.

Keller, K. L. (2003). Brand synthesis: The multidimensionality of brand knowledge. Journal of Consumer Research, 29(4), 595-600.

Kim, J. H. (2010). Determining the factors affecting the memorable nature of travel experiences. Journal of Travel \& Tourism Marketing, 27(8), 780-796.

Kim, J. H. (2013). A cross-cultural comparison of memorable tourism experiences of American and Taiwanese college students. Anatolia, 24(3), 337-351.

Kim, J. H. (2018). The impact of memorable tourism experiences on loyalty behaviors: The mediating effects of destination image and satisfaction. Journal of Travel Research, 57(7), 856-870.

Kim, J., \& Hatfield, E. (2004). Love types and subjective well-being: A cross-cultural study. Social Behavior and Personality: An International Journal, 32(2), 173-182.

Kim, J. H., \& Ritchie, J. B. (2014). Cross-cultural validation of a memorable tourism experience scale (MTES). Journal of Travel Research, 53(3), 323-335.

Kim, J-H., Ritchie, J. R. B., \& McCormick, B. (2012). Development of a scale to measure Memorable Tourism Experiences. Journal of Travel Research, 51(12), 12-25.

Kim, J.-H., Ritchie, J. R. B., \& Vincent, V. W. S. (2010). The effect of memorable experience on behavioral intentions in tourism: A structural equation modeling approach. Tourism Analysis, 637-648.

Kline, R. B. (2005). Principal and practice of structural equation modeling. New York: The Guilford Publication.

Knobloch, U., Robertson, K., \& Aitken, R. (2017). Experience, emotion, and eudaimonia: A consideration of tourist experiences and well-being. Journal of Travel Research, 56(5), 651- 662 . 
Köker, S. (1991). Comparing the level of the life satisfaction of the normal adolescents and adolescents with problems. Unpublished doctoral dissertation, Ankara University, Ankara.

Larsen, S. (2007). Aspects of a psychology of the tourist experience. Scandinavian Journal of Hospitality and Tourism, 7(1), 7-18.

Lean, G. L. (2012). Transformative travel: A mobilities perspective. Tourist Studies, 12(2), 151-172.

Lee, T. H., \& Crompton, J. (1992). Measuring novelty seeking in tourism. Annals of Tourism Research, 19(4),732-751.

Loureiro, S. M. C., Breazeale, M., \& Radic, A. (2019). Happiness with rural experience: Exploring the role of tourist mindfulness as a moderator. Journal of Vacation Marketing, 25(3), 279-300.

Manfredo, M. J. (1989). An investigation of the basis for external information search in recreation and tourism. Leisure Sciences, 11(1), 29.

Maslow, A. H. (1943). Preface to motivation theory. Psychosomatic medicine, 5, 85-92.

McConkey, R., \& Adams, L. (2000). Matching short break services for children with learning disabilities to family needs and preferences. Child Care, Health and Development, 26(5), 429-444.

Nawijn, J. (2011). Determinants of daily happiness on vacation. Journal of Travel Research, 50(5), 559-566.

Neal, J. D., Sirgy, M. J., \& Uysal, M. (2004). Measuring the effect of tourism services on travelers' quality of life: Further validation. Social Indicators Research, 69(3), 243-277.

Novelli, M., \& Robinson, M. (2005). Niche Tourism: an introduction. In M. Novelli (Ed.), Niche Tourism: Contemporary issues, trends and cases (pp. 1-14). Oxford: Elsevier.

Noy, C. (2004). Israeli backpackers: Narrative, interpersonal communication, and social construction. In C. Noy \& E. Cohen (Eds.), Israeli backpackers and their society: A view from afar (pp. 111-158). New York: University of New York Press.

Ooi, C.-S. (2005). A theory of tourism experiences: The management of attention. In T. O'Dell \& P. Billing (Eds.), Experience scopes (pp. 51-68). Denmark: Copenhagen Business School Press.

Ortony, A., \& Turner, T. J. (1990). What's basic about basic emotions?. Psychological Review, 97(3), 315.

Otto, J. E., \& Ritchie, J. B. (1996). The service experience in tourism. Tourism Management, 17(3), 165-174.

Pearce, D. G. (1987). Tourism Today: A Geographical Analysis. Harlow: Longman.

Pine, B. J. P., \& Gilmore, J. H. (2011). The experience economy. Boston: Harvard Business Review Press.

Podsakoff, P., MacKenzie, S., Lee, J., \& Podsakoff, N. (2003). Common method biases in behavioral research: a critical review of the literature and recommended remedies. Journal of Applied Psychology, 88(5), 879-903.

Prayag, G., Hosany, S., Muskat, B., \& Del Chiappa, G. (2017). Understanding the relationships between tourists' emotional experiences, perceived overall image, satisfaction, and intention to recommend. Journal of Travel Research, 56(1), 41-54.

Ryan, R. M., \& Deci, E. L. (2001). On happiness and human potentials: A review of research on hedonic and eudaimonic well-being. Annual Review of Psychology, 52(1), 141-166.

Sharma, P., \& Nayak, J. K. (2019). Understanding memorable tourism experiences as the determinants of tourists' behaviour. International Journal of Tourism Research, 21(4), 504-518. 
Sharpley, R., \& Jepson, D. (2011). Rural tourism: A spiritual experience?. Annals of Tourism Research, 38(1), 52-71.

Shrout, P., \& Bolger, N. (2002). Mediation in experimental and nonexperimental studies: New procedures and recommendations. Psychological Methods, 7, 422-445.

Sirgy, M. J., Rahtz, D. R., Cicic, M., \& Underwood, R. (2000). A method for assessing residents' satisfaction with community-based services: a quality of life perspective. Social Indicators Research, 49(3), 279-316.

Slåtten, T., Krogh, C., \& Connolley, S. (2011). Make it memorable: customer experiences in winter amusement parks. International Journal of Culture, Tourism and Hospitality Research, 5(1), 80-91.

Steger, M. F., Frazier, P., Oishi, S., \& Kaler, M. (2006). The meaning in life questionnaire: Assessing the presence of and search for meaning in life. Journal of Counseling Psychology, 53(1), 80-93.

Steiner, C. J., \& Reisinger, Y. (2006). Understanding existential authenticity. Annals of Tourism Research, 33(2), 299-318.

Sthapit, E. (2018). A netnographic examination of tourists' memorable hotel experiences. Anatolia, 29(1), 108-128.

Sthapit, E., \& Coudounaris, D. N. (2018). Memorable tourism experiences: Antecedents and outcomes. Scandinavian Journal of Hospitality and Tourism, 18(1), 72-9.

Tsai, C. T. (2016). Memorable tourist experiences and place attachment when consuming local food. International Journal of Tourism Research, 18(6), 536-548.

Tukamushaba, E. K., Xiao, H., \& Ladkin, A. (2016). The effect of tourists' perceptions of a tourism product on memorable travel experience: Implications for destination branding. European Journal of Tourism, Hospitality and Recreation, 7(1), 2-12.

Tung, V. W. S., \& Ritchie, J. B. (2011a). Exploring the essence of memorable tourism experiences. Annals of Tourism Research, 38(4), 1367-1386.

Tung, V. W. S., \& Ritchie, J. B. (2011b). Investigating the memorable experiences of the senior travel market: An examination of the reminiscence bump. Journal of Travel E Tourism Marketing, 28(3),331-343.

Turner, L., \& Ash, J. (1975). The golden hordes: International tourism and the pleasure periphery. London: Constable and Company, Ltd.

Uriely, N. (2005). The tourist experience: conceptual developments. Annals of Tourism Research, 32(1), 199-216.

Uriely, N., Schwartz, Z., Cohen, E., \& Reichel, A. (2002). Rescuing hikers in Israel's deserts: Community altruism or an extension of adventure tourism?. Journal of Leisure Research, 34(1), 25-36.

Uzzell, D. (1998). Interpreting our heritage: a theoretical interpretation. In D. Uzzell \& R. Ballantyne (Eds.), Contemporary issues in heritage and environmental interpretation (pp. 11-25). London: The Stationary Office.

Vada, S., Prentice, C., \& Hsiao, A. (2019). The influence of tourism experience and wellbeing on place attachment. Journal of Retailing and Consumer Services, 47, 322-330.

Wang, N. (1999). Rethinking authenticity in tourism experience. Annals of Tourism Research, 26(2), 349-370.

Watson, D., Clark, L. A., \& Tellegen, A. (1988). Development and validation of brief measures of positive and negative affect: the PANAS scales. Journal of Personality and Social Psychology, 54(6), 1063.

Westbrook, R. A., \& Oliver, R. L. (1991). The dimensionality of consumption emotion patterns and consumer satisfaction. Journal of consumer research, 18(1), 84-91. 
Wilson, E., \& Harris, C. (2006). Meaningful travel: Women, independent travel and the search for self and meaning. Tourism, 54, 161-172.

Yolal, M., \& Karacaoglu, S. (2017). An evaluation of tourism potential and sustainability in Cappadocia, Turkey. 5th UNESCO Unitwin Conference on Local Identity and Tourism Management on World Heritage Sites, Coimbra, Portugal, 18-22 April, 2017.

Zhang, H., Wu, Y., \& Buhalis, D. (2018). A model of perceived image, memorable tourism experiences and revisit intention. Journal of Destination Marketing $\mathcal{E}$ Management, 8, 326-336.

Zhong, Y. Y. S., Busser, J., \& Baloglu, S. (2017). A model of memorable tourism experience: The effects on satisfaction, affective commitment, and storytelling. Tourism Analysis, 22(2), 201-217. 